\title{
GP commissioners not spending enough on mental health, claims Labour
}

This News story (BMJ 2014;349:g4857, doi:10.1136/bmj.g4857) states that figures from Public Health England (PHE) show that Merton CCG in southwest London has the highest proportion of its population with a common mental health disorder (31\%). However, PHE have confirmed that the $31 \%$ figure was incorrect, and have updated their data to show that common mental health disorder prevalence for Merton is $16 \% .^{1}$
Public Health England. Common mental health disorders. http://fingertips.phe.org.uk profile-group/mental-health/profile/common-mental-disorders/data\#gid/8000026/pat/46/ ati/19/page/1/par/E39000018/are/E38000105

Cite this as: BMJ 2014;349:95080

๑ BMJ Publishing Group Ltd 2014 